\title{
EL DERECHO DE LA UNIÓN EUROPEA COMO FRENO A LA HUIDA DEL DERECHO ADMINISTRATIVO
}

\author{
Carmen Chinchilla Marín \\ Catedrática de Derecho Administrativo \\ Universidad de Alcalá
}

\begin{abstract}
RESUMEN
El derecho de la Unión Europea ha supuesto un freno a la huida del derecho administrativo. Así se pone de manifiesto en el ámbito de los contratos públicos y en relación con la disminución de entidades de naturaleza privada en el sector público, como consecuencia de los principios de estabilidad presupuestaria y sostenibilidad financiera.
\end{abstract}

Palabras clave: huida del derecho administrativo; contratos públicos; entes públicos; estabilidad presupuestaria; sostenibilidad financiera.

\begin{abstract}
European Union Law has limited the escape from Administrative Law. This is evidenced in the area of public contracts and by the decrease in private entities in the public sectors a result of the principles of budget stability and financial sustainability.
\end{abstract}

Key words: escape from Administrative Law; public contracts; public entities; budget stability; financial sustainability. 


\section{SUMARIO}

I. INTRODUCCIÓN.-II. El ETERNO PROBLEMA DE LA HUIDA DEL DERECHO ADMINISTRATIVO.-III. El DERECHO DE LA UNIÓN EUROPEA COMO FRENO A LA HUIDA DEL DERECHO ADMINISTRATIVO: 1. La contratación pública: definición autónoma, amplia y funcional del concepto «organismo público-poder adjudicador». 2. Los entes instrumentales de las Administraciones públicas: límites a su creación y mantenimiento derivados de los principios de estabilidad presupuestaria y sostenibilidad financiera. 2.1. La estabilidad presupuestaria y la sostenibilidad financiera como nuevos valores estructurales y condicionantes de (toda) la actuación de (todos) los entes que integran el sector público. 2.2. La definición del SEC-2010 de lo que debe considerarse -a efectos del cómputo del déficit-como "Administración pública». 2.3. La reducción del gasto público y la necesidad de racionalizar el sector público. - - IV. ConcLusión.

\section{INTRODUCCIÓN}

En los años noventa, en España, se escribió mucho de la huida del derecho administrativo y esta misma Revista publicó un excelente trabajo de S. del Saz que todavía hoy puede leerse como si no hubiesen pasado ya casi treinta años ${ }^{1}$.

Los problemas allí denunciados y las críticas tan sólidamente argumentadas al fenómeno de la huida del derecho administrativo siguen estando de actualidad y, en mi opinión, hay razones para pensar que la huida no ha hecho más que acentuarse y que las críticas que la profesora del Saz y otros muchos autores hicieron al mencionado fenómeno siguen siendo muy pertinentes, todavía hoy. Por eso creo que tiene sentido reflexionar en este número de la Revista de Administración Pública, treinta años después del ingreso de nuestro país en lo que hoy es la Unión Europea (UE), sobre si el derecho de la UE ha supuesto o no un freno a la huida del derecho administrativo.

\section{EL ETERNO PROBLEMA DE LA HUIDA DEL DERECHO ADMINISTRATIVO}

Como es bien sabido, huir del derecho administrativo es lo que hacen las Administraciones públicas cuando «se escapan» de los límites, controles y garantías que son propios del derecho administrativo mediante, sobre todo, pero no únicamente, la creación de entes instrumentales de naturaleza privada, especialmente de sociedades mercantiles. Y digo que no únicamente creando personificaciones de

1 Vid. S. DEL SAZ Cordero (2004), «La huida del Derecho Administrativo: últimas manifestaciones. Aplausos y críticas», Revista de Administración Pública, 133, págs. 57-98. 
derecho privado porque, en mi opinión, también se huye del derecho administrativo cuando artificiosamente se califican de «privados» algunos contratos o algunos bienes cuya sustancia es, indiscutiblemente, pública.

Ciertamente, hablar de «huir», de "escaparse» y hasta de «fugarse» tiene una connotación negativa y, por tanto, quienes no consideran la huida del derecho administrativo un problema podrían reprocharme y, con razón, que la descripción del fenómeno puede hacerse de manera más aséptica y objetiva, diciendo, por ejemplo, que no hay que hablar de huida, sino, simplemente, de la sustitución de un derecho, el derecho administrativo, por otro, es decir, el derecho privado. Sin embargo, a estas alturas del siglo XXI no puede seguir diciéndose que la huida del derecho administrativo no es un problema porque, en mi opinión, sí lo es, por las razones que expondré a continuación, y porque la realidad se ha encargado de demostrar que las Administraciones públicas, por lo general, no han creado personificaciones jurídico-privadas para realizar actuaciones mercantiles o de contenido predominantemente económico, sino para realizar actividades de naturaleza claramente pública. Prestar un servicio público como la sanidad a través de fundaciones o proveerse de centros penitenciarios a través de una sociedad mercantil no parece que sean actividades de carácter mercantil.

Pero, además, la huida del derecho administrativo es también la huida del derecho administrativo general hacia el derecho administrativo especial, y la Ley 6/997, de Organización y Funcionamiento de la Administración General del Estado (LOFAGE), es un buen ejemplo de ello. El legislador siempre está haciendo el mismo esfuerzo — desde la Ley de Entidades Estatales Autónomas de 1958 hasta la más reciente de 2015 (Ley de Régimen Jurídico del Sector Público, LRJSP), pasando por la LOFAGE (1997)—: tipificar las clases de entes instrumentales y otorgarles un régimen jurídico homogéneo, de acuerdo con sus características, para luego hacer listados interminables de entes «especiales» que no se sujetan a ese derecho común de los entes instrumentales y, por supuesto, dejando siempre abierta la posibilidad, inevitable, de que la ley de creación de cada ente establezca para el mismo el régimen jurídico que considere pertinente. Y ni que decir tiene que para el legislador que crea un ente instrumental, ese ente, el último que ha creado, es el más singular de todos y el que más necesitado está de excepciones al régimen general.

Y, finalmente, la huida no es sólo del derecho administrativo, sino también, y cabría decir, «sobre todo», del derecho financiero y presu- 
puestario, como muy bien ha expuesto J. Pascual García ${ }^{2}$, poniendo de manifiesto cómo las cinco instituciones que definen, en lo esencial, el régimen económico-financiero de los entes del sector público (Presupuesto, Contabilidad, Tesoro Público, Estabilidad presupuestaria y Control financiero) se aplican con distinto alcance según se trate de entes del sector público «administrativos»o «empresariales». Hay, por tanto, también, una huida del presupuesto, de la contabilidad pública, del control financiero, etc. que nos obliga a contemplar el fenómeno de la huida como la escapatoria de los controles, filtros, límites y obligaciones que el derecho público impone a las Administraciones públicas, y no por capricho, sino como forma de garantizar el mandato constitucional que tienen de servir con objetividad y eficacia al interés general (artículo 103 CE) y, cómo no, con el fin también de garantizar el respeto a los derechos e intereses legítimos de los particulares en sus relaciones con las Administraciones públicas.

La huida sigue siendo, pues, un problema, también en nuestros días, aunque ya apenas se escriban artículos doctrinales sobre ello.

En efecto, la huida sigue siendo un problema porque, en primer lugar, «salirse» del derecho público, en el sentido del término aquí utilizado, esto es, como derecho de los entes públicos, es entrar en un mundo en el que no es fácil saber - con la precisión y el rigor que exige saberlo cuando tienes que dar una respuesta concreta y hallar una solución a un problema real y no meramente teórico-cuál es exactamente el derecho aplicable. Porque, en efecto, cuando un ente del sector público o una actuación suya (por ejemplo, un contrato) quedan extramuros del derecho público, porque han sido calificados de "privados», no puede decirse que eso no constituya un problema, argumentando que, al quedar fuera del derecho público, entra en el ámbito de aplicación del derecho privado. El problema existe, en mi opinión, por dos razones. La primera, porque entrar en el derecho privado, en ocasiones, equivale, sencillamente, a regirse por el principio de la autonomía de la voluntad de las partes y del principio de legalidad, en su significado de vinculación negativa a la ley, principios ambos que encajan mal cuando de realizar actividades públicas se trata. Y es que, insisto una vez más, el problema de la huida no ha sido ni es que se creen entes instrumentales de naturaleza privada para realizar actividades mercantiles, sino que se creen para realizar actividades netamente administrativas. Y la segunda razón para pensar que la huida del derecho público suele llevar aparejado el problema de

2 J. Pascual García (2010), «La huida del Derecho Administrativo, del Presupuesto y de los controles financieros por los nuevos entes del sector público», Presupuesto y Gasto público, 60 , págs. $109-128$. 
no saber cuál es, exactamente, el derecho aplicable al caso es porque, muchas veces, la huida del derecho público a lo que te lleva es a un terreno todavía menos seguro que el de la aplicación, pura y dura, del derecho privado. Me refiero a que te lleva a una tierra de nadie como lo es, en mi opinión, a la que conducen todas esas normas de derecho administrativo que, cuando excluyen de su ámbito de aplicación determinadas actuaciones (piénsese en los contratos excluidos de la Ley de Contratos del sector público) o determinadas personificaciones (piénsese, por ejemplo, en las sociedades mercantiles en la legislación de bienes públicos), suelen añadir fórmulas tan ambiguas como la de que esos contratos quedan, no obstante, sujetos a «los principios» de la ley de que se trate, para resolver las dudas y lagunas que puedan plantearse, o que esas sociedades mercantiles se regirán por el derecho privado, salvo lo que, de las leyes de derecho público, les resulte de aplicación.

Ahí está el problema, es decir, en saber, en primer lugar, cuándo hay una laguna o, simplemente, una falta de regulación de requisitos o procedimientos, precisamente porque se está ante un ente del sector público sujeto al derecho privado; en segundo lugar, en saber qué normas, de las miles que integran el derecho público, hay que entender que resultan de aplicación a un ente privado del sector público del que se dice que queda sometido al derecho privado, excepto en lo que, del Derecho público, le resulte (específicamente o no) de aplicación. Y en tercer y último lugar, el problema está en determinar cómo aplicar solo «los principios» (por ejemplo, la publicidad y concurrencia, o la capacidad para contratar) sin entrar de lleno en las «reglas» (por ejemplo, los procedimientos de contratación o las prohibiciones de contratar). A un contrato patrimonial, para el que su ley específica (ley especial) ha establecido que se regirá por el derecho privado, pero que está sujeto a los «principios» de las leyes sobre patrimonio de las Administraciones públicas (ley general), ¿se le aplican las prohibiciones de contratar porque la Ley de Patrimonio, para los contratos sobre bienes patrimoniales, haya establecido que les resultan de aplicación las prohibiciones de contratar de la legislación de contratos? ¿ $\mathrm{O}$, por el contrario, dado que la ley especial, para ese contrato, ha establecido que se rigen por el derecho privado, pero con sujeción a los principios (no a las reglas) de la legislación general de bienes públicos, le aplicamos, en cuanto a la capacidad de contratar las prohibiciones de contratar, pero no al cien por cien, sino de forma más flexible o relajada? ¿Y hasta dónde habría que rebajarlas, de tal manera que se pudiera considerar suficiente para cumplir con un principio (un ente público solo debería hacer un contrato sobre un bien público, aunque 
sea patrimonial, con un sujeto que tenga capacidad para contratar, en el sentido positivo y negativo del término) pero sin tener que llegar al cumplimiento íntegro de una norma?

Cabría objetar que el problema planteado no es un problema irresoluble porque se supera con el talento y la pericia que se le presume a un buen funcionario o a un buen abogado, pero asumiendo que así sea, la huida del derecho público no se agota en un problema de inseguridad jurídica y de dificultad de definir, en cada caso concreto, cuál es el derecho exactamente aplicable, sino que tiene una trascendencia práctica que trastoca, cuando no erosiona, los pilares del Estado social y democrático de derecho.

En segundo lugar, la razón por la que considero que la huida del Derecho Administrativo y del derecho público, en general, sigue siendo un problema en el siglo XXI, es porque «salirse» del derecho público es, como se ha puesto de manifiesto, salirse de los controles financieros a los que se somete el gasto público cuando quienes lo realizan son los entes del sector público de naturaleza administrativa. Y así, de las tres modalidades de control interno que la Ley 47/2003, General Presupuestaria (LGP) prevé - la intervención, el control financiero permanente y la auditoría pública-, el primero, que es el único que supone un control previo y, además, encaminado a garantizar el cumplimiento de los procedimientos de gestión de gastos, ingresos y aplicación de fondos públicos, sólo se aplica a la Administración General del Estado y a sus organismos autónomos. De ahí para abajo, el control financiero se aplica en sus modalidades más flexibles, esto es, control financiero permanente (para las entidades públicas empresariales, por ejemplo) o únicamente la auditoría pública (para las sociedades mercantiles) ${ }^{3}$.

Cuando el control financiero «se relaja» puede ocurrir lo que la realidad actual nos está mostrando, es decir, que por donde salen los controles del gasto puede entrar la corrupción o, simplemente, que no es poco, el despilfarro de los fondos públicos. Y es que, en efecto, nuestro derecho permite crear un ente instrumental, de naturaleza privada, para, por ejemplo, gestionar el pago de subvenciones, lo que demuestra, una vez más, que no se acude a las formas de personificación privada solamente para realizar actividades mercantiles, sino cien por cien administrativas como lo es, sin duda, la que consiste en disponer del dinero público poniéndolo en manos privadas con el fin de fomentar el desarrollo de actividades de interés general.

\footnotetext{
3 J. Pascual García (2010: 118-123).
} 
En tercer y último lugar, si considero que, todavía hoy, la huida del derecho público sigue siendo un problema es porque creo que cuando dicha huida se realiza mediante la creación de personificaciones de derecho privado, que es la fórmula más habitual de hacerlo, aumenta el gasto público, lo cual, en tiempos de crisis, y también en los de no-crisis, es sencillamente inasumible.

Cuando en el Inventario de Entes del sector público vemos que existen, en la totalidad del sector público (estatal, autonómico, local y Seguridad Social), más de 3.500 entes públicos, y que la mayor parte de ellos son sociedades mercantiles, fundaciones y $\operatorname{consorcios}^{4}$, hay que preguntarse, en primer lugar, cuántos de ellos realizan actividades mercantiles y, en segundo lugar, cuántos de ellos era, realmente, necesario crear. Si pensamos que la realidad nos muestra ejemplos de cómo para prestar un servicio público municipal varios ayuntamientos han creado varias mancomunidades que, a su vez, han creado un consorcio que, a su vez, ha creado una sociedad mercantil, ¿'se puede decir, de verdad, que lo de la huida del derecho administrativo no es un problema?

III. El DEREcho de la Unión Europea como FRENo a la HUIDA DEL DERECHO ADMINISTRATIVO

$\mathrm{Al}$ igual que, como en la vida misma, el que huye no suele volver al lugar del que huyó por su propia voluntad, tampoco las Administraciones públicas (con el legislador que les ha dado cobertura), han reprimido, durante muchos años, su más que probada vocación por la huida del derecho público. Ha tenido que ser el derecho de la UE el que, en determinados ámbitos, ha servido de freno - creo que efectivo- a la huida del derecho público.

El mecanismo es conocido por todos: un derecho común para -hoy por hoy - 28 Estados que hablan diferentes lenguas, no sólo en el sentido lingüístico del término, sino también jurídico, necesita tener una «lengua común» para evitar que pueda eludirse el cumplimiento de ese derecho con el solo hecho de dar una u otra forma jurídica o nombrar a las cosas de una manera o de otra. Por eso, para hacer efectivo el cumplimiento del derecho (el famoso «efecto útil»), se crean conceptos y categorías que se definen con criterios sustantivos y materiales que, trascendiendo las formas, los nombres y las naturalezas jurídicas, se

4 http://www.igae.pap.minhap.gob.es/sitios/igae/esES/ContabilidadNacional/InformacionGeneral/Documents/Entidades_incluidas_en_el_sector_de_las_ Administraciones_P\%c3\%bablicas.pdf. Actualizado a 3 de febrero de 2015. 
interesan solamente por la esencia de las cosas. Y con ello, en último término, se consigue que los Estados miembros no se «escapen» de la aplicación del derecho de la UE, por mucho que lo intenten.

Aunque no sean los únicos, dos son, en mi opinión, los ámbitos en los que se ha dejado sentir con más intensidad este efecto de freno a la huida del derecho del derecho público: el de la contratación pública y el de la personificación y proliferación de entes públicos con forma jurídico-privada, como consecuencia de la aplicación de los principios de estabilidad presupuestaria y estabilidad financiera. En ellos voy a centrar, por tanto, mis reflexiones.

\section{La contratación pública: definición autónoma, amplia y funcional del concepto "organismo público-poder adjudicador»}

Un elemento esencial a partir del cual se construye el derecho europeo de los contratos públicos es el referido a los sujetos a los que resultan de aplicación sus normas. El derecho de la UE se aplicará o no, y se aplicará con una intensidad o con otra, en función del objeto que tenga el contrato y de su cuantía, pero el presupuesto previo es que se trate de un contrato celebrado por un poder adjudicador. Por eso, la noción de poder adjudicador es el concepto clave, el que traza la línea de lo que queda sujeto al derecho de la UE sobre contratación pública y de lo que queda fuera del mismo.

La fuerza de ese concepto y su virtualidad para poner freno al escapismo de la aplicación del derecho de la UE sobre contratos públicos reside, por un lado, en la propia definición del concepto, y, por otro, en su interpretación por el Tribunal de Justicia de la UE ${ }^{5}$.

La definición de "poder adjudicador» ha estado siempre hecha a partir de conceptos funcionales o materiales que, por encima de la forma que adopten los sujetos contratantes y, no digamos, del nombre con que sean designados en los diferentes Estados, se centran en lo que hacen esos sujetos y en cómo y con qué lo hacen. De ahí, que las Directivas consideren "poderes adjudicadores» al Estado, a los entes territoriales (regionales y locales), a los organismos de derecho público y las asociaciones constituidas por uno o más de dichos entes o de dichos organismos de derecho público. A su vez, y a los efectos de las Directivas

5 Me remito, por ofrecer un resumen claro de esta cuestión, a C. CHINCHILla MARín (2011), «La jurisprudencia del TJUE sobre contratos públicos (I): ámbito subjetivo y objetivo de aplicación de las Directivas», en M. SÁnchez Morón (dir.) y J. Del Olmo Alonso (coord.), El Derecho de los contratos públicos en la UE y sus Estados miembros (págs. 33-79), Lex Nova. 
sobre contratación pública, se considera «organismo público» cualquier organismo:

a) creado específicamente para satisfacer necesidades de interés general que no tengan carácter industrial o mercantil,

b) dotado de personalidad jurídica propia y

c) que esté financiado mayoritariamente por el Estado, los entes territoriales u otros organismos de derecho público, o cuya gestión esté sujeta a la supervisión de dichas autoridades u organismos, o que tenga un órgano de administración, de dirección o de supervisión, en el que más de la mitad de los miembros sean nombrados por el Estado, los entes territoriales u otros organismos de Derecho público.

Esta noción, funcional y amplia, no hubiera tenido, sin embargo, el efecto que ha surtido para los Estados miembros, como lo demuestran las condenas del TJEU a muchos de ellos, si el Tribunal de Justicia de la UE no hubiera hecho una interpretación de las características que a continuación describo.

En efecto, en sus numerosas sentencias sobre las Directivas de contratos públicos, el Tribunal de Justicia ha partido siempre de la premisa de que sus normas deben interpretarse de modo tal que quede garantizada su plena eficacia o el denominado «efecto útil» de las mismas. Ello ha llevado al Tribunal a definir una serie de criterios interpretativos que pueden quedar resumidos en los siguientes términos: en primer lugar, la interpretación de las normas comunitarias sobre contratos públicos ha de hacerse desde el propio derecho europeo y no desde los derechos nacionales, pues de otro modo no se conseguiría una interpretación uniforme de las mismas; en segundo lugar, la interpretación debe tener carácter funcional, esto es, ha de trascender de los elementos puramente formales o nominalistas y buscar el significado material de las nociones que utilizan las Directivas y demás normas aplicables en la materia. En tercer y último lugar, debe hacerse una interpretación amplia, cuando se trata de determinar, en clave positiva, el ámbito de aplicación de las normas comunitarias y, por el contrario, estricta, cuando se trata de determinar el significado de los conceptos que implican la exclusión de dicha aplicación.

Con base en una interpretación de estas características, el Tribunal ha concluido en diversas ocasiones, por lo que respecta a España, y por poner solo dos ejemplos, que el derecho español no es pertinente para determinar si una sociedad mercantil pública debe ser considerada o no 
como poder adjudicador (asunto Siepsa; Sentencia de 16 de octubre de 2003), ni para establecer si lo que se califica como «convenio de colaboración» entre un Ministerio y una sociedad mercantil pública es o no un contrato a los efectos de las Directivas (asunto Correos y Telégrafos S.A.; Sentencia de 18 de diciembre de 2007). Los criterios con los que se define lo que es un poder adjudicador — dirá el TJUE— son conceptos autónomos del derecho europeo.

El caso Siepsa constituye para mí uno de los mejores ejemplos de la jurisprudencia del TJUE en la materia y de los que, seguramente, más ha influido en la evolución de nuestra legislación de contratos.

En este supuesto, el Tribunal de Justicia tuvo que determinar si la empresa estatal española cuyo objeto era, en esencia, la construcción de instalaciones penitenciarias, tenía o no la consideración de poder adjudicador. Pocos casos han sido resueltos con tanta claridad y contundencia por el Tribunal de Justicia, quien basó su decisión en los siguientes razonamientos: a) Siepsa fue creada específicamente para satisfacer necesidades que están intrínsecamente vinculadas al orden público, al constituir una condición necesaria para ejercer el poder represivo del Estado; b) no existe un mercado para los bienes y servicios que ofrece; c) aun suponiendo que realice sus actividades con ánimo lucrativo, queda descartada la posibilidad de considerar que la búsqueda de tales beneficios constituya en sí el primer objetivo de esta sociedad; antes al contrario, su principal objetivo es contribuir a la realización de la política penitenciaria del Estado; d) con independencia de si existe un mecanismo oficial de compensación de posibles pérdidas, parece poco probable que la sociedad mercantil pública haya de soportar los riesgos económicos derivados de su actividad, pues, habida cuenta de que la realización de su función constituye un elemento esencial de la política penitenciaria del Estado español, resulta verosímil que, como único accionista, dicho Estado tome todas las medidas necesarias al objeto de evitar una posible quiebra de Siepsa; e) en estas circunstancias, existe la posibilidad de que, en un procedimiento de adjudicación de un contrato público, se guíe por consideraciones distintas a las meramente económicas. Sobre la base de todo ello, el Tribunal concluye que «las necesidades de interés general para cuya satisfacción se creó específicamente dicha sociedad no tienen carácter industrial o mercantil».

Con este precedente - y otros muchos, ya sean referidos a España, que los ha habido, ya a otros Estados miembros de la Unión-, el legislador aprobó, en 2007, una nueva Ley de Contratos, en la que no sólo cambió significativamente el título (pasando de llamarse Ley de Contratos de las Administraciones públicas a Ley de Contratos del Sec- 
tor público), sino que, sobre todo, cambió radicalmente de perspectiva a la hora de definir el ámbito subjetivo de aplicación, haciéndolo de una forma muy amplia, con el propósito, declarado en la Exposición de Motivos, de «ajustar el ámbito de aplicación de la Ley a las directivas comunitarias, así como para no dejar entidades del sector público exentas de regulación...», para lo cual, y con el objetivo de "asegurar el cierre del sistema», incluía una cláusula residual reproduciendo literalmente la definición de «organismo público» de la Directiva, en cuanto poder adjudicador, garantizando así que, «en cualquier caso, el ámbito de aplicación de la Ley se extienda a cualquier organismo o entidad que, con arreglo a la norma comunitaria, deba estar sometido a sus prescripciones».

A partir de esta Ley, con sus sucesivas modificaciones que han seguido ampliando el ámbito subjetivo de su aplicación, queda claro que, de acuerdo con el derecho de la UE, es irrelevante que la entidad contratante adopte una forma jurídico-privada - por ejemplo, la de sociedad mercantil- para que, solo por ello, quede exenta de cumplir las normas europeas de contratación pública. Con lo cual, y ese es el efecto limitador de la huida, sabemos que se vista de lo que se vista la entidad contratante, y se llame como se llame, estará sujeta al derecho de la UE si realiza actividades de interés general que no son mercantiles o industriales (como, por ejemplo, según el TJUE, construir y gestionar cárceles; prestar determinados servicios funerarios; imprimir los documentos oficiales de identidad de los ciudadanos como pasaportes y carnet de identidad; construir y alquilar viviendas a precio moderado; o prestar determinados servicios forestales y, además, está bajo la estrecha dependencia (financiera o de otro tipo) de un poder adjudicador, de tal manera que éste puede influir en sus decisiones en materia de contratos.

2. Los entes instrumentales de las Administraciones públicas: límites a su creación y mantenimiento derivados de los principios de estabilidad presupuestaria y sostenibilidad financiera

2.1. La estabilidad presupuestaria y la sostenibilidad financiera como nuevos valores estructurales y condicionantes de (toda) la actuación de (todos) los entes que integran el sector público

Los profesores García de Enterría y Fernández Rodríguez, en el Curso de Derecho Administrativo, vienen sosteniendo desde principios de los años noventa que las personificaciones para actuar en régimen de 
derecho privado pueden justificarse cuando la Administración pretende actuar en el mercado libre y como cualquier empresario, pero que carecen, sin embargo, de toda justificación en otro caso, concluyendo que ni el legislador ni menos aún la Administración pueden dispensar a una organización inequívocamente pública de las vinculaciones que la Constitución le impone ${ }^{6}$. La realidad demuestra que las cosas no han ido por esos derroteros y que, antes bien, tanto el legislador como las Administraciones públicas han abusado de la creación de entidades privadas y las han utilizado para llevar a cabo actividades administrativas y no de carácter mercantil.

Frente a ese abuso, la UE ha supuesto también un freno, probablemente el más efectivo, a través de las exigencias derivadas de los principios de estabilidad presupuestaria y sostenibilidad financiera.

La importancia de la estabilidad presupuestaria y, más ampliamente, del equilibrio en las finanzas públicas ${ }^{7}$ se pone claramente de manifiesto con la reforma constitucional operada en septiembre de 2011 que, como es sabido, dio una nueva redacción al artículo 135 de la Constitución. Con ello, según la Exposición de Motivos de la reforma, se consagra, con el mayor rango normativo, un valor verdaderamente estructural y condicionante de la capacidad de actuación del Estado, con el efecto de limitar y orientar la actuación de los poderes públicos.

Muy resumidamente expuesto, el artículo 135 de la Constitución consagra el principio de estabilidad presupuestaria; prohíbe al Estado y a las comunidades autónomas incurrir en un déficit estructural que supere los márgenes establecidos por la UE, lo que significa que les permite incurrir en un cierto déficit; impone a los entes locales el equilibrio presupuestario y, por tanto, no les permite incurrir en déficit alguno; limita el endeudamiento público; y atribuye «prioridad absoluta» al pago de los intereses y el capital de la deuda pública.

A pesar de que el precepto constitucional sólo hable de «Administraciones públicas», lo cierto es que el conjunto de reglas que lo integran se aplican a todo el sector público y no exclusivamente a las Administraciones públicas. Y ello es así no solo porque la Exposición de Motivos de la reforma constitucional utilice la fórmula omnicomprensiva $-\mathrm{y}$ poco

6 E. García de Enterría y T. R. Fernández Rodríguez (2015), Curso de Derecho Administrativo, t. I (págs. 440-441), Madrid: Civitas. Antes, por ejemplo, en la $6^{\text {a }}$ ed. del Curso (1993), pág. 390.

7 J. García-Andrade Gómez (2012), «La reforma del artículo 135 de la Constitución española», Revista de Administración Pública, 187, págs. 31-66; (2013), "La adopción de la estabilidad presupuestaria en la Constitución Española», Ius Publicum Network Review, 3, págs. 1-69 (versión ampliada del trabajo publicado en la Revista de Administración Pública, 187).

J. García Roca y M. A. Martínez Lago (2013), Estabilidad presupuestaria y consagración del freno constitucional al endeudamiento, Madrid: Civitas. 
correcta, en mi opinión- de "poderes públicos» ${ }^{8}$, para decir que su actuación, la de todos los poderes públicos, queda limitada por el principio de estabilidad presupuestaria, sino también, y sobre todo, porque las leyes dictadas en desarrollo o cumplimiento del precepto constitucional (Ley Orgánica 2/2012, de Estabilidad Presupuestaria y Sostenibilidad Financiera; Ley 27/2013, de Racionalización y Sostenibilidad de la Administración Local y Ley 15/2014, de Racionalización del Sector público y otras medidas de reforma administrativa) ponen claramente de manifiesto, como no podía ser de otra manera, que los principios de estabilidad presupuestaria y sostenibilidad financiera son aplicables a todos los entes que integran el sector público, ya sea éste estatal, autonómico o local ${ }^{9}$.

Estabilidad presupuestaria y sostenibilidad financiera — ese «nuevo principio general en gestación", como lo ha calificado el profesor T. R. Fernández ${ }^{10}$ - se imponen a todos los entes públicos, cualquiera que sea su naturaleza y su forma, lo que implica, por tanto, que, aunque se adopten formas de personificación privada, las reglas de estabilidad presupuestaria y sostenibilidad financiera son también de aplicación a todos estos entes "privados» del sector público.

$\mathrm{Y}$, precisamente, para evitar que a la hora de hacer las cuentas y presentarlas ante la UE, puedan eludirse las obligaciones derivadas de los principios de estabilidad presupuestaria y sostenibilidad financiera, mediante el mecanismo de interponer un ente instrumental de naturaleza privada, para que los gastos que genere la actividad que realice no computen en el cálculo del déficit, la UE ha establecido un sistema común de cuentas —el SEC ${ }^{11}$ — y, por su parte, las leyes españolas sobre estabilidad presupuestaria y sostenibilidad financiera han terminado por remitirse a ese sistema para definir el ámbito de aplicación subjetiva de dichas leyes, diciendo que el sector público se considera integrado

\footnotetext{
${ }^{8}$ No es correcto, en mi opinión, calificar como poderes públicos a las entidades del sector público que adoptan forma y naturaleza privada (las sociedades mercantiles o las fundaciones), sencillamente porque no lo son; y no lo son, precisamente, porque no ejercen potestades, por más que recientemente las leyes hayan reconocido, como asumiendo una anomalía que, como tal, no debería tener consagración legal, que puede haber sociedades mercantiles que ejerzan potestades públicas (artículos 2.2.b de la Ley 39/2015 del Procedimiento Administrativo Común de las Administraciones Públicas, LPAC, y artículos 2.2.b y 113 de la Ley 40/2015 de Régimen Jurídico del Sector Público).

9 Vid. las Sentencias del Tribunal Constitucional de 2011, números 157, 185 a 189, 195 a 199 y 203.

10 T. R. Fernández Rodríguez (2016), «Reflexiones sobre la sostenibilidad de los servicios públicos, un nuevo principio general en gestación», Revista de Administración Pública, 200, págs. 439-450.

11 Reglamento n ${ }^{\circ}$ 549/2013, del Parlamento Europeo y del Consejo, de 21 de mayo de 2013, relativo al Sistema Europeo de Cuentas Nacionales y Regionales de la Unión Europea, conocido como SEC-2010, y que derogó el Reglamento no 2223/1996, del Consejo de 25 de junio de 1996, conocido como SEC-95.
} 
por «las unidades» que, de acuerdo con el SEC, se incluyen en el sector "Administraciones públicas» y en los correspondientes subsectores, igualmente definidos conforme al SEC.

2.2. La definición del SEC-2010 de lo que debe considerarse - a efectos de cómputo del déficit-como "Administración pública»

De acuerdo con el $S E C-2010^{12}$, para determinar si una operación que genere gastos incide o no en el déficit público, deben tomarse en consideración dos elementos: uno, subjetivo, referido al tipo de entidad que realiza la operación; y el otro objetivo, referido al tipo de operación y, en concreto, a si el activo derivado de esa operación (por ejemplo, una infraestructura) entra en el balance de la entidad pública y, por tanto, consolida e incrementa el déficit público o si, por el contrario, no entra en el balance de la entidad pública y, por consiguiente, no consolida y no tiene, por tanto, impacto en el déficit público.

Centrándonos en el aspecto subjetivo, que es el que nos interesa a los efectos de este trabajo, el concepto clave para el SEC-2010 es el de "sector Administraciones públicas» que incluye «todas las unidades institucionales que son productores no de mercado cuya producción se destina al consumo individual o colectivo, que se financian mediante pagos obligatorios efectuados por unidades pertenecientes a otros sectores y que efectúan operaciones de redistribución de la renta y de la riqueza nacional» ${ }^{13}$.

A su vez, el sector Administraciones públicas se divide en cuatro subsectores: la Administración central, las Administraciones regionales, las Administraciones locales y los Fondos de la Seguridad Social ${ }^{14}$.

Para determinar si un ente queda incluido o no en el sector $A d$ ministraciones públicas, deben producirse las tres circunstancias siguientes: (i) que sea una unidad institucional, es decir, una entidad económica que se caracteriza por su autonomía de decisión en el ejercicio de su función principal ${ }^{15}$; (ii) que esté bajo el control de una

12 Vid. el Reglamento citado en nota anterior y Eurostat (2016), Manual on Goverment déficit and debt, disponible en: http://ec.europa.eu/eurostat/web/government-finance-statistics/ methodology/manuals.

13 Para el SEC-2010, apartado 1.57, las unidades institucionales de un país se clasifican en cinco sectores: las sociedades no financieras; las sociedades financieras; las Administraciones públicas; los hogares y las instituciones sin ánimo de lucro al servicio de los hogares.

14 Apartado 2.113 del SEC-2010.

15 De acuerdo con el SEC-2010 (apartado 2.12), tener autonomía de decisión significa: a) ser titular de bienes o activos con facultad de disposición sobre ellos y poder intercambiar su propiedad mediante operaciones con otras unidades institucionales; b) tener capacidad para tomar decisiones económicas y realizar actividades económicas de las que es responsable ante la ley; c) tener capacidad para contraer deudas y otras obligaciones y suscribir contratos en 
Administración pública ${ }^{16}$; y (iii) que sea una unidad institucional no de mercado.

Finalmente, el SEC-2010 define la unidad de no mercado como aquella que ofrece toda o la mayor parte de su producción a terceros de forma gratuita o a precios económicamente no significativos ${ }^{17}$. Para saber si una unidad vende o no a precios económicamente significativos habrá que aplicar el test del 50\%, consistente en determinar si las ventas cubren, al menos, el 50\% de los costes de producción de la unidad a lo largo de un período que se prolongue, al menos, durante tres años ${ }^{18}$. Si se da esa circunstancia, entonces será una unidad de mercado ${ }^{19}$. Previamente, para determinar qué se considera venta, a estos efectos, el SEC analiza quién es el comprador de esa unidad institucional, distinguiendo las tres situaciones siguientes: que la producción se venda principalmente a terceros (sociedades y hogares); que se venda solo a las Administraciones públicas, con o sín licitación pública; o que se venda a las Administraciones públicas y a terceros ${ }^{20}$.

A través de todos estos criterios que, a su vez, se completan con la definición de otros conceptos como el de «ventas» $\mathrm{o}$ «costes de producción», el SEC define, pues, de manera funcional, y prescindiendo por completo de la forma y naturaleza jurídica que adopten las entidades en cada Estado miembro, cuándo el gasto de dichas entidades tiene impacto en el déficit público y cuándo no.

Con ello, y por la vía de los números y de las cuentas, el derecho de la UE ha creado un mecanismo de freno a la huida de las obligaciones de estabilidad presupuestaria y de sostenibilidad financiera, de tal manera que el fenómeno de la huida encuentra, finalmente, el que debería ser el límite más efectivo a su expansión: saber que los entes del sector público

nombre propio; y d) tener capacidad para elaborar un conjunto completo de cuentas en el que se incluyen documentos contables que recojan la totalidad de sus operaciones llevadas a cabo durante el primer período contable, así como un balance de activos y pasivos.

16 De acuerdo con el SEC-2010 (apartado 2.38), la Administración pública puede asegurarse el control de una sociedad mediante una disposición legal, decreto o reglamento especial que le autorice a determinar la política de la sociedad. Los principales factores que deben tenerse en cuenta a la hora de decidir si una sociedad está controlada por las Administraciones públicas son: a) la titularidad pública de la mayoría de los derechos de voto; b) el control público del consejo de administración o del órgano ejecutivo; c) el control público del nombramiento o de la revocación del personal directivo; d) el control público de los principales comités de la entidad; e) la posesión pública de una acción de oro; f) la existencia de normativas específicas; g) que la Administración represente el grueso de la demanda; y h) que la Administración haga préstamos a la sociedad. A todo ello se añade que un único indicador puede bastar para determinar que hay control en algunos casos, mientras que en otros, el control vendrá determinado por varios de estos indicadores.

17 Apartado 20.19.

18 Eurostat (2016: apartado 34).

19 Ibid. (apartado 20.29).

20 Ibid. (apartados 20.23 a 20.27). 
—todos, y no solo los de naturaleza jurídico-pública- cuando gastan incrementan el déficit público, y cuando se endeudan incrementan la deuda pública.

Qué reflejo haya tenido todo esto en las leyes aprobadas en los últimos años en España es lo que trataré de exponer en el siguiente apartado.

\subsection{La reducción del gasto público y la necesidad de racionalizar el sector público}

Las obligaciones derivadas de los principios de estabilidad presupuestaria y sostenibilidad financiera han tenido como efecto la disminución del número de entes que integran el sector público. Si todos los entes del sector público deben ser sostenibles y por sostenibilidad se entiende la capacidad para financiar los compromisos de gasto presente y futuros dentro de los límites de déficit, deuda pública y morosidad de deuda comercial (artículo 4 de la Ley Orgánica 2/2012), es claro que deben imponerse límites, en primer lugar, a la creación de entes instrumentales y, en segundo lugar, a su mantenimiento. Las dos leyes que, en mi opinión, han establecido las medidas más importantes en la materia son la Ley 27/2013, de racionalización y sostenibilidad de la Administración local y la Ley 40/2015, de Régimen jurídico del Sector público.

La Ley 27/2013, de racionalización y sostenibilidad de la Administración local, estableció una serie de medidas para reducir la dimensión del sector público local, lo cual, a la vista de las cifras que habían alcanzado en los últimos años las entidades instrumentales de las Administraciones locales, no sólo resultaba razonable, sino que era necesario ${ }^{21}$.

La primera medida consistió en prohibir a las entidades locales, mientras estén sujetas a un plan económico-financiero o a un plan de ajuste, adquirir, constituir o participar en la constitución, directa o indirectamente, de nuevos organismos, entidades, sociedades, consorcios, fundaciones, unidades y demás tipos de entes ${ }^{22}$.

La segunda medida consistió en exigir el saneamiento de las entidades instrumentales que se encontrasen en situación de desequilibrio financiero. Para ello se previó que debían presentar un plan de correc-

21 En 2009, año en el que se alcanza la cifra más alta de entidades instrumentales del sector público local, había 5.957. Vid. el Informe Entidades que integran el Sector Público Local. Situación a 31 de marzo de 2016, p. 2. http://www.minhap.gob.es/Documentacion/Publico/DGCFEL/ Sector\%20p\%C3\%BAblico\%20local-Nota_31_03_2016.pdf

22 Disposición adicional novena, apartado $1^{\circ}$ de la Ley 7/1985, Reguladora de las Bases del Régimen Local (LBRL), en su redacción dada por la Ley 27/2013. 
ción, en el plazo de dos meses, y si el 31 de diciembre de 2014 no habían corregido el déficit, la entidad quedaría automáticamente disuelta el 1 de diciembre de $2015^{23}$.

La tercera y última medida consiste en la prohibición de crear entidades instrumentales de segundo nivel, es decir, entidades instrumentales controladas por otras entidades instrumentales que, a su vez, lo estén por las entidades locales ${ }^{24}$. Para los entes instrumentales secundarios ya existentes que no estuviesen en situación de superávit, equilibrio o resultados positivos de explotación, se establecía la necesidad de adscribirse o vincularse directamente a una entidad local, o bien disolverse; todo ello en el plazo de tres meses desde la entrada en vigor de la ley. De no hacerlo así, se preveía su disolución automática transcurridos seis meses desde la entrada en vigor de la $\mathrm{Ley}^{25}$.

La Ley 40/2015, de Régimen Jurídico del Sector Público (LRJSP), ha venido a culminar el proceso de reducción del sector público que habían emprendido ya otras leyes, como la ya citada 27/2013, de racionalización y sostenibilidad de la Administración local, la Ley 2/2011, de Economía sostenible, la Ley 3/2013, de creación de la Comisión Nacional de los Mercados y la Competencia y la Ley 15/2014, de racionalización del Sector público y otras medidas de reforma administrativa.

En su Exposición de Motivos, la LRJSP resume en qué va a concretarse la idea - presente en todas esas leyes que la han precedido- de que el sector público debe ser sostenible en el tiempo. Y en lo que se ha concretado es en establecer un marco normativo para impedir la creación de órganos y entidades innecesarios y redundantes; para asegurar la eficacia y la eficiencia de los entes públicos; y para ejercer sobre ellos una supervisión continua que permita evaluar el cumplimiento de los objetivos que justificaron su creación, y cuestionar su mantenimiento cuando aquellos se hayan agotado o exista otra forma más eficiente de alcanzarlos.

Con base en ello, la LRJSP establece una serie de disposiciones, comunes para todos los entes institucionales del sector público, y otras, específicas para los del sector público estatal.

Por lo que se refiere a las disposiciones comunes a todos los entes públicos, tres son las reglas que la LRJSP establece:

${ }^{23}$ Disposición adicional novena, apartado $2^{\circ}$ de la LBRL No obstante, los plazos se ampliaban hasta el 31 de diciembre de 2015 y hasta el 1 de diciembre de 2016, cuando las entidades en desequilibrio estuviesen prestando los servicios esenciales de abastecimiento domiciliario y depuración de aguas; recogida, tratamiento y aprovechamiento de residuos; y transporte público de viajeros.

${ }^{24}$ Disposición adicional novena, apartado $3^{\circ}$ de la LBRL.

25 Disposición adicional novena, apartado $4^{\circ}$ de la LBRL. 
- la sujeción de la actuación de todos los entes del sector institucional a los principios de legalidad, eficiencia, estabilidad presupuestaria, sostenibilidad financiera y transparencia en su gestión (artículo 81.1);

- la obligación para todos los entes del sector público institucional de inscribir su creación, transformación o extinción en el Inventario de Entidades del Sector público estatal, autonómico y local, siendo dicha inscripción requisito necesario para obtener el número de identificación fiscal definitivo de la Agencia Estatal de Administración Tributaria (artículos 82 y 83), y

- la obligación para todas las Administraciones públicas de disponer de un sistema de supervisión continua de sus entidades institucionales, con el objeto de comprobar la subsistencia de los motivos que justificaron su creación y su sostenibilidad financiera. Este sistema de supervisión deberá incluir la formulación periódica de propuestas de transformación, mantenimiento o extinción (artículo 81).

Por lo que respecta al sector institucional público estatal, la Ley empieza por establecer una lista cerrada de los tipos de entes que integran el sector público estatal ${ }^{26}$ y prohíbe crear o ejercer el control efectivo, directa o indirectamente, sobre ningún otro tipo de entidad que no sea una de las enumeradas en la lista, con independencia - termina diciendo el precepto- de su naturaleza y régimen jurídico (artículo 84). La ley, pues, en la línea de lo que han venido haciendo (y contradiciendo) las leyes que vienen regulando, desde los años cincuenta, los entes instrumentales de las Administraciones públicas, hace un esfuerzo por tipificar y homogeneizar y, por consiguiente, por evitar la huida del derecho administrativo general o común hacia un derecho administrativo especial o atípico. Es dudoso, sin embargo, que la prohibición llegue a tener efectividad, pues bastará una norma con rango de ley para crear un tipo de ente que no esté en la lista de los entes del sector público estatal, sin que ninguna consecuencia práctica parece que pueda derivarse de una hipotética salida de la lista cerrada de entidades que defi-

\footnotetext{
${ }^{26}$ Los entes que integran el sector público estatal son, según el artículo 84.1 de la LRJSP, los siguientes:

Los organismos públicos, los cuales se clasifican en:

$1^{\circ}$ Organismos autónomos.

$2^{\circ}$ Entidades públicas empresariales.

Las autoridades administrativas independientes.

Las sociedades mercantiles estatales.

Los consorcios.

Las fundaciones.

Los fondos sin personalidad jurídica.

Las universidades públicas no transferidas.
} 
ne el artículo 84.1 de la LRJSP. Y no sólo es eso; es que la propia Ley ha «excluido» de la aplicación del Derecho administrativo común a las universidades (artículos 2.2.c de la LPAC y 2.2.c y 84.3 de la LRJSP); a los órganos constitucionales (disposición adicional quinta LPAC) y las autoridades administrativas independientes (artículo 110 LRJSP). Con el agravante de que, sin embargo, ha sometido al derecho administrativo común, aunque no sabemos a cuánto de ese derecho, a las sociedades mercantiles cuando ejerzan potestades públicas, lo que, en puridad, no debería ocurrir nunca, si de verdad sólo se acudiera a esa forma de personificación jurídica que es la sociedad mercantil para realizar actividades mercantiles.

Más efectivas me parecen las exigencias que la LRJSP establece en relación con la creación de los entes del sector público institucional y con su régimen de supervisión continua; las referidas a la creación de medios propios; las que ponen límites a la transformación de un ente de naturaleza pública en uno de naturaleza privada; las que regulan la fusión de entes públicos; y, finalmente, las relativas a las causas de disolución. Me referiré muy brevemente a todas ellas, subrayando lo que, en mi opinión, resulta más importante.

Por lo que se refiere a la creación de entes públicos, cuando se trate de organismos públicos estatales, ésta deberá ir precedida de un plan inicial de actuación en el que, entre otras cosas, se motive la necesidad de su creación; se justifique que sus funciones no pueden ser ejercidas por otro ente ya existente y que su creación no supondrá una duplicidad. Asimismo, deberá concretarse la forma jurídica propuesta y justificarse que la elegida resulta más eficiente frente a otras alternativas que se hayan descartado (artículo 91). Por lo que respecta a las sociedades mercantiles, tendrá que justificarse, también, la necesidad de su creación en los mismos términos y, además, explicar que la forma jurídica de sociedad resulta más eficiente que la creación de un organismo público u otras alternativas de organización (artículo 114).

Respecto del control de eficiencia y supervisión continua, todas las entidades del sector público estatal estarán sometidas a una supervisión permanente por el Ministerio al que estén adscritas y por el Ministerio de Hacienda que consistirá, entre otras cosas, en verificar la subsistencia de las circunstancias que justificaron su creación, su sostenibilidad financiera, y la concurrencia de la causa de disolución consistente en el incumplimiento de los fines que justificaron su creación o que su subsistencia no resulte el medio más idóneo para lograrlos. Asimismo, el Ministerio de adscripción realizará un control de eficacia que tendrá por objeto evaluar el cumplimiento de los objetivos y la adecuada utilización 
de los recursos. Los resultados de la evaluación deberán plasmarse en un Informe que, según las conclusiones alcanzadas, podrá contener recomendaciones de mejora, o una propuesta de transformación o supresión del ente público (artículo 85).

Para la creación de un medio propio se exige una memoria justificativa, que deberá ser informada por la Intervención de la Administración General del Estado, en la que, además de acreditar que dispone de medios suficientes e idóneos para realizar prestaciones en el sector de actividad que se corresponda con su objeto social, tendrá que justificarse que el medio propio es una opción más eficiente que la contratación pública y que resulta sostenible y eficaz, aplicando criterios de rentabilidad económica; o bien que resulta necesario por razones de seguridad pública o de urgencia en la necesidad de disponer de los bienes o servicios suministrados por el medio propio o servicio técnico (artículo 86).

En lo que respecta a las transformaciones de las entidades del sector público institucional, se prevé que cualquier organismo autónomo, entidad pública empresarial, sociedad o fundación podrá transformarse y adoptar la naturaleza jurídica de cualquiera de las otras citadas. La transformación se llevará a cabo, conservando su personalidad jurídica, por cesión ${ }^{27}$ o integración global, en unidad de acto, de todo el activo y el pasivo de la entidad transformada, con sucesión universal de derechos obligaciones, y se realizará por Real Decreto, aunque ello suponga modificar la ley de creación del ente transformado. Todo son, pues, facilidades para la transformación, salvo cuando la transformación sea de ente de naturaleza pública a ente de naturaleza privada (o de organismo autónomo a entidad pública empresarial), en cuyo caso la ley exige una memoria en la que deben justificarse, entre otras cosas, por qué el ente no puede ejercer sus funciones manteniendo su naturaleza jurídica originaria; el ahorro que va a suponer la transformación; y la acreditación de que no va a haber duplicidades. La transformación exige, igualmente, el informe preceptivo de la Intervención General de la Administración del Estado que valorará el cumplimiento de todos los requisitos exigidos para la transformación de entes del sector público institucional (artículo 87).

Por lo que se refiere a la fusión entre organismos públicos, la LRJSP la facilita también, estableciendo que se podrá hacer mediante la extinción e integración en un nuevo organismo público, o bien mediante su extinción por absorción por otro organismo público ya existente. La fusión se llevará a cabo mediante norma reglamentaria, aunque

27 La Ley habla de «cesión», pero, en mi opinión, en sentido estricto, no puede haber tal "cesión» porque no hay dos personas jurídicas distintas, sino una, solo que con su naturaleza jurídica transformada. 
suponga la modificación de la ley de creación, y si la fusión implica la creación de un nuevo organismo tendrá que cumplir con los requisitos de creación de los organismos públicos, a los que antes he hecho referencia (artículo 94).

Finalmente, en relación con las causas de disolución, por lo que respecta a los organismos públicos, me interesa destacar dos causas de disolución que son las definidas en los apartados b) y e) del artículo 96 de la LRJSP. De acuerdo con la primera, el organismo público deberá disolverse cuando del seguimiento del plan de actuación resulte el incumplimiento de los fines que justificaron la creación del organismo o que su subsistencia no es el medio más idóneo para lograrlos y así se concluya en el control de eficiencia o de supervisión continua. De acuerdo con la segunda, el organismo deberá disolverse cuando se encuentre en situación de desequilibrio financiero durante dos ejercicios presupuestarios consecutivos. A este respecto, la situación de desequilibrio se referirá, para los entes que tengan la consideración de Administración pública a efectos del Sistema Europeo de Cuentas, a su necesidad de financiación en términos del citado sistema, mientras que para los demás entes se entenderá como la situación de desequilibrio manifestada en la existencia de resultados brutos negativos de explotación en dos ejercicios contables consecutivos. En ambos casos, la Ley establece unos plazos para que se proceda a la disolución y dispone que, si no se cumplieran, los organismos quedarán automáticamente disueltos «y no podrán realizar ningún acto jurídico, salvo los estrictamente necesarios para garantizar la eficacia de su liquidación y extinción».

A la vista de los distintos mecanismos que han quedado descritos creo que cabe albergar alguna esperanza en que servirán de límite a la creación desenfrenada de entidades públicas, particularmente las de naturaleza privada, así como al mantenimiento de las que no son sostenibles o el tiempo ha demostrado que resultan innecesarias.

\section{CONCLUSión}

A lo largo de estas páginas he reflexionado en torno a dos ejemplos, que no son los únicos, pero sí que creo que son los más importantes, de cómo la UE ha supuesto un freno a la huida del derecho administrativo. Un freno en el doble sentido de, por un lado, haber creado y definido conceptos y categorías con la finalidad de evitar que, adoptando formas de personificación jurídico-privada, las Administraciones públicas que las crean queden extramuros del derecho público (en el caso examinado, 
del derecho público europeo de los contratos) y, por otro lado, de haber conseguido frenar el fenómeno de la proliferación de los entes públicos con las reglas de contención del déficit público.

Se dirá que, en este segundo caso, el freno a la huida del derecho público se produce de manera indirecta, y así es, pero creo que no por ello es menos eficaz. En efecto, y como ha quedado expuesto, el Sistema Europeo de Cuentas ha establecido un concepto amplio de «sector Administraciones públicas» cuya aplicación supone que, por encima de los nombres y las formas, los entes del sector público, salvo que se financien en el mercado en los términos que ya han quedado expuestos, «cuentan» a efectos del cálculo del déficit público. Ello supone un freno a la huida desde el momento en que muchos de esos entes instrumentales que han proliferado a lo largo de los años son entes de naturaleza jurídico-privada, con lo cual, optar por estas formas, tan poco adecuadas para la realización de las actividades propias de las Administraciones públicas, ya no será un medio para alcanzar el objetivo buscado, es decir, escapar de los rigores del derecho público.

Y, en último término, lo que, en todo caso, supone la reducción del sector público es un freno al gasto público y, con ello, al déficit público y a la deuda pública.

Las leyes a las que aquí me he referido, con sus respectivas medidas, ponen de manifiesto la firme voluntad del legislador de seguir reduciendo el número de entidades que integran el sector público. Una reducción que, afortunadamente, podemos decir que viene siendo la tendencia en nuestro país en los últimos años, tal y como lo demuestran los distintos Informes sobre la reordenación del sector público, en los que se pone de manifiesto que, desde 2010 hasta hoy, los entes instrumentales han disminuido considerablemente, tanto en el sector público estatal como en el sector público autonómico y local ${ }^{28}$.

Así, el sector público estatal ha pasado de tener 473 entidades institucionales en 2010 a 296 en 2015. Las comunidades autónomas han

${ }^{28} \mathrm{Vid}$. Informe sobre el impacto del sector público autonómico en la actividad económico-financiera de las Comunidades Autónomas, http://www.lamoncloa.gob.es/serviciosdeprensa/notasprensa/Documents/030215InformeImpacto\%2001_07_2014.pdf; Informe sobre la reordenación del sector público autonómico, http://www.minhap.gob.es/Documentacion/Publico/PortalVarios/ FinanciacionTerritorial/Autonomica/Informe\%20Reordenación\%20SP\%20a\%2001-04-2012. pdf; Entidades que integran el Sector público local, situación a 31 de marzo de 2016; Inventario de entidades pertenecientes al sector de las Administraciones públicas. En estos informes se toma como punto de referencia el 1 de julio de 2010 porque es a partir de ese año cuando se firman los Acuerdos del Consejo de Política Fiscal y Financiera (Acuerdos 1/2010 y 5/2012). En el Informe sobre la reordenación del sector público autonómico se especifica que no se integra la información del sector público del País Vasco porque no se dispone de la información necesaria para ello. Sin embargo, en el Inventario de entidades del sector público, publicado por primera vez el 1 de diciembre de 2015, sí que aparecen las cifras del sector público autonómico vasco. 
pasado de las 2163 que tenían en 2010 a 1253 en 2015. Finalmente, las entidades locales han pasado de tener 5224 en 2010 a 2017 en 2015.

Las formas jurídicas con un mayor porcentaje de reducción han sido los consorcios, con un 49,2\%, seguidos de las sociedades mercantiles, con un $46,2 \%$ y de las fundaciones con un $29,9 \%$. Y todo ello ha supuesto un ahorro que, en el sector autonómico, ha sido de 2106422,14 miles de euros ${ }^{29}$.

A la vista de estas cifras, cabe confiar en que la tendencia iniciada en 2010 se mantenga y que, en consecuencia, las Administraciones públicas sigan realizando su función de servir al interés general con eficacia y eficiencia, sin incurrir en los gastos que supone crear entidades instrumentales con el objeto que huir de la aplicación del derecho público. Puesto que, como he tratado de exponer en estas páginas, cada vez resultará más difícil la huida del derecho público, es de esperar que solamente se acuda a la creación de entidades instrumentales, sobre todo de naturaleza jurídico-privada, cuando esté realmente justificado.

29 En los informes citados, aparte de la cifra de ahorro que ha supuesto la reducción del sector público autonómico, se indica la correspondiente a los entes locales, pero sólo referida a los años 2013-2015 e indicando que se dispone solamente de información de 351 de los 570 suprimidos en ese período. De acuerdo con ello, se indica que 151 de los entes suprimidos tuvieron resultados negativos en el ejercicio anterior a su supresión por importe total de 40,52 millones de euros, a lo que hay que sumar los gastos de explotación y el gasto no financiero en el que incurrían las entidades suprimidas, que se elevó a 484, 09 millones de euros. 
